\title{
The prediction of water resource and management method in Shandong province
}

\author{
Zijun Song \\ School of Electrical \& Electronic Engineering, North China Electric Power University, Hebei 071000, \\ China
}

18233274031@163.com

Keywords: time series, supply-demand ratio, prediction intervene

\begin{abstract}
In order to help provide access to clean water for all citizens of the world, we build an evaluation model, analyze corresponding reasons and impacts of water scarcity, and provide a targeted intervention plan. Shandong province where water is heavily overloaded is chosen as our study object. Methods of grey prediction, time series and interpolation are used to predict population size, urbanization level and water situation of Shandong in 15 years. In addition, with the help of multi-objective genetic algorithms, an intervention plan, covering three schemes, is designed for Shandong. Influences that the intervention plan has on surrounding areas are presented as well.
\end{abstract}

\section{Introduction}

According to UN statistics, the presence of water shortages quarter of the world's population. There are two main reasons for the shortage: the lack of physical and economic deficiencies. Refers to the lack of physical properties is not enough water to meet the needs of a particular territory. Lack of economic means an area of water, but because of poor management and lack of infrastructure limits access to clean water. In addition, population growth and climate change makes the problem even more serious water shortages. Can the entire world access to clean water has become a problem of continuing concern.

\section{Model assumptions}

1. Do not consider the impact of disasters on water supply and demand in the extreme

2. The prediction model does not consider the impact of policy changes on the number of population

3. States urban population is the same as domestic water demand

4. The current national water according to the current industry structure has optimal allocation

\section{Establishment and solution of the model}

\subsection{Evaluation Model of water supply and demand balance}

Firstly, the advantages and disadvantages of the scarcity of water resources evaluation index 'per capita water resources' current international use, taking into account on the basis of the dynamic effects of various factors on water supply and demand, the introduction of industrial distribution, urbanization, water resource development, water quality, water distribution time, spatial distribution coefficient, proposed a "supply and demand ratio" $\mathrm{R}$ indicators to measure water level. $\mathrm{R}=\mathrm{S} / \mathrm{D}$, where, $\mathrm{S}$ represents an area of water supply, $\mathrm{D}$ represents the total demand of water resources of a region.

According factors, the per capita water resources to improve.

$$
\mathrm{R}=\frac{S}{D}=\frac{W_{0} \times \beta_{0} \times \beta_{1} \times \beta_{2}+W_{1}}{A \times P \times \alpha_{0} \times \alpha_{1}}
$$


Where $\alpha_{0}, \alpha_{1}, \beta_{0}, \beta_{1}, \beta_{2}$ denote coefficient distribution coefficient for the industry, the level of urbanization coefficient, coefficient of water resources development, water quality coefficient, temporal distribution of water resources.

For any region, the number of people in the know, the basic annual water consumption and water use include domestic water consumption, urbanization, water quality and rainfall data such circumstances, can be drawn, "supply and demand ratio" $\mathrm{R}$, so for all regions As long as there is a corresponding statistical data, it can be used to evaluate the model. $\mathrm{R}$ smaller the more serious water shortages, usually less than $1 \mathrm{R}$, but because there is a certain subjectivity A value is set, there will be water-rich regions $\mathrm{R}$ value greater than 1 .

\subsection{Water forecasting 3.2 Shandong Province}

According to the method of determining the coefficient of variables, find relevant data in Shandong Province in recent years, to six and the number of variable factors to predict the population to determine the supply and demand ratio in 2030 in Shandong Province. From the supply and demand ratio in 2030 to illustrate the living conditions of Shandong Province and the possible outstanding issues.

Gray prediction method of agricultural water, industrial water, water consumption.

Tab.1 Prediction of Sectors’ Water Consumption

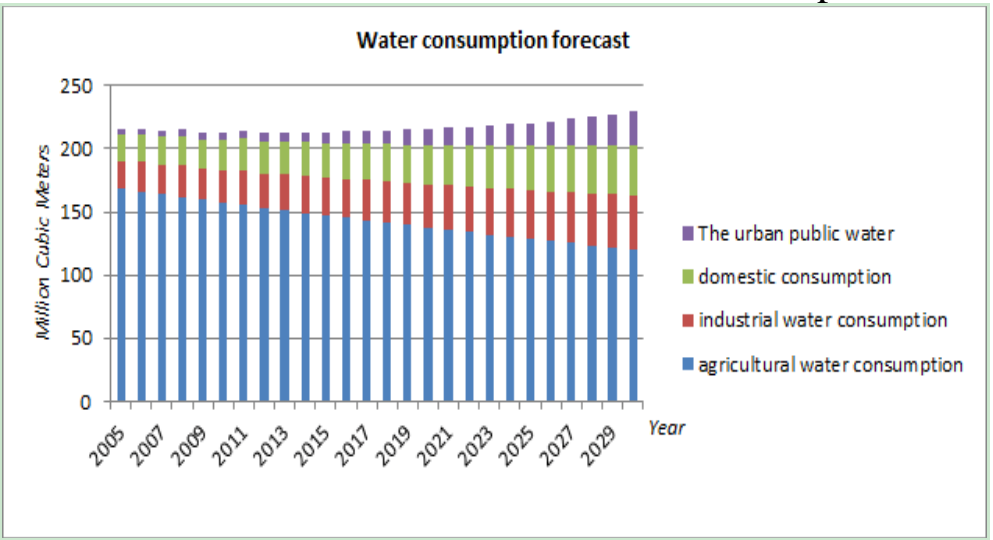

Based on the above predicted values, coefficient variations are computed as follows:

$$
\begin{aligned}
& \beta_{0}=\text { total water consumption } \\
& \beta_{1}=1-\text { contamination coefficient } \\
& \alpha_{0}=\frac{\text { total water consumption }}{\text { domestic water consumption }}
\end{aligned}
$$

$\alpha_{1}$ denotes the urbanization level, $\beta_{2}=1$

The supply-demand ratio of 2030 is 0.195, having little difference with that of $2014(0.194)$. According to figure 9, the supply-demand ratio remains in a low value, indicating serious water shortage and high water pressure. By 2021, the value of supply-demand ratio is increasing, suggesting slight remission of water shortage issue. But after 2021, its value again declines, indicating the increase of water pressure. Among the factors which influence supply-demand ratio, population size and urbanization level present exponential growth, greatly contributing to the increase of water demand. Due to the increased proportion of domestic water consumption, coefficient of industry structure becomes smaller. That leads to a benign development for supply-demand ratio. There is no obvious change in development coefficient, so it has little impact on supply. Problem about water contamination is greatly eased, which can help increase water supply.

\subsection{Intervention Plan}

Based on results of the above predicted models, main drivers of water scarcity in Shandong include large population size and rapid growth rate, increased urbanization level, unreasonable distribution of industry structure and water development problem. 
The design and analysis of our intervention plan mainly focus on the above factors. The intervention effect and its feasibility are discussed through data. And the strengths and weaknesses of our intervention plan is analyzed as well.

According to the actual situation in Shandong province and predicted results, problems such as sewage treatment are being or will be gradually solved without extra intervention, so our intervention plan does not consider them.

\subsection{1 urban optimization layout based on water distribution}

Conflict between water supply and urban development is currently getting worse. In the process of urbanization in Shandong, urban optimization layout will be a key to solve water shortage problem. Based on water distribution, the urban optimization layout model is established to help solve the water problem in Shandong.

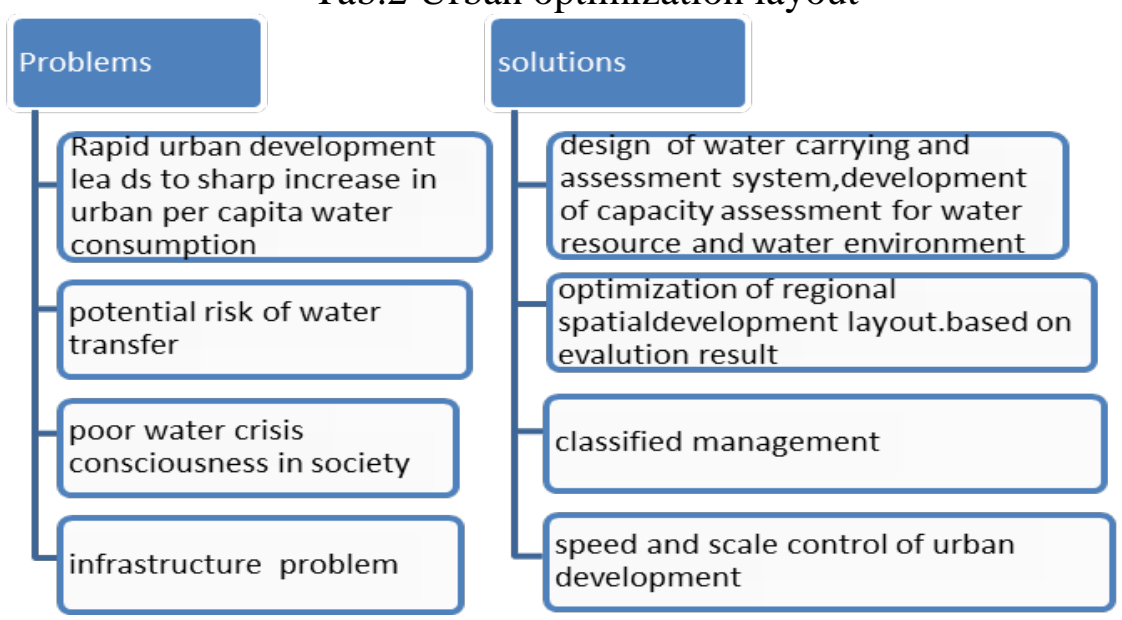

\subsection{2 adjustment based on the type of crop virtual water distribution}

Shandong Province is a large traditional agricultural province, more than $75 \%$ of total agricultural water, wherein the major food crops of winter wheat, summer corn in the production of water accounts for a sizeable proportion of wheat and maize crop water use efficiency in agricultural water level in Shandong Province and water Resources in Shandong Province has an important relationship.

According to Shandong Province, the main crop virtual water content of water, production water footprint analysis, production of major crops in Shandong Province put forward the following measures and recommendations:

(1) increase agricultural production inputs. Irrigation technology, agricultural machinery and other modern agricultural production factors can increase agricultural production efficiency, reduce production water footprint of crops, effectively improve the efficiency of water use in Shandong Province.

(2) optimize the agricultural planting structure and layout. Scientific basis for all food production in Shandong Province Water Footprint regional differences, the water footprint of crop production in the smaller areas of intensive production, lower crop production water footprint larger areas of crop acreage.

\subsubsection{Intervention Results Forecast and Analysis}

The layout of the city water resources based optimization decisions will limit the level of urbanization rapid development, according to the natural distribution of water resources and carrying capacity to layout and urban development, better planning of urban population in 2015, for example, the decision to join the post-layout optimization cities level factor can be reduced to $32 \%$ to $35 \%$, inhibited the growth of urbanization.

Shandong Province this agricultural country, based on the type of crop virtual water distribution adjustment programs in reducing consumption of virtual water flows and played a certain role. 
Tab.3 Intervention results forecast

\begin{tabular}{ccccccccc}
\hline year & $\mathbf{2 0 1 5}$ & $\mathbf{2 0 1 6}$ & $\mathbf{2 0 1 7}$ & $\mathbf{2 0 1 8}$ & $\mathbf{2 0 1 9}$ & $\mathbf{2 0 2 0}$ & $\mathbf{2 0 2 1}$ & $\mathbf{2 0 2 2}$ \\
\hline$\alpha_{0}$ & 7.22 & 6.96 & 6.69 & 6.43 & 6.18 & 5.95 & 5.73 & 5.53 \\
$\alpha_{1}$ & 0.32 & 0.30 & 0.28 & 0.26 & 0.23 & 0.23 & 0.22 & 0.20 \\
$\boldsymbol{R}$ & 0.22 & 0.23 & 0.24 & 0.24 & 0.25 & 0.26 & 0.27 & 0.27 \\
year & $\mathbf{2 0 2 3}$ & $\mathbf{2 0 2 4}$ & $\mathbf{2 0 2 5}$ & $\mathbf{2 0 2 6}$ & $\mathbf{2 0 2 7}$ & $\mathbf{2 0 2 8}$ & $\mathbf{2 0 2 9}$ & $\mathbf{2 0 3 0}$ \\
$\alpha_{0}$ & 5.33 & 5.15 & 4.97 & 4.80 & 4.65 & 4.50 & 4.36 & 4.22 \\
$\alpha_{1}$ & 0.20 & 0.18 & 0.16 & 0.16 & 0.16 & 0.17 & 0.17 & 0.16 \\
$\boldsymbol{R}$ & 0.28 & 0.28 & 0.29 & 0.29 & 0.30 & 0.30 & 0.31 & 0.31 \\
\hline
\end{tabular}

The results showed that the intervention, to limit the level of urbanization development, and reduce agricultural water, the comparison is not obvious when supply and demand plus interference increasing trend, indicating that the water situation will be eased. However, we can see that the ratio of supply and demand is still low, which is less of total water resources in Shandong Province and the population density of the basic situation in the province is very linked. Shandong have to continue to intervene in the future water supply and demand balance eased at the same time.

\section{Conclusion}

Evaluation model of supply and demand than to join a series of dynamic factors in 'per capita water resources' on the basis of international evaluation to improve, has a good theoretical basis. Reflect both changes in water environment security situation, but also reflects the socio-economic situation of water environment in which safety can correctly evaluate the current state of development and utilization of water resources, forecast the development trend of water environmental safety.

Water forecasting model were used to bias the smallest prediction model based on historical data distribution characteristics, follow-up work to provide accurate predictions. Forecast results for the current development situation, the analysis of causes of water shortage in Shandong Province to provide a great help.

\section{References}

[1]Shaofeng Jia, Junyan Zhang, Shifeng Zhang. "Regional Water Resources Stress and Water Resources Security Appraisement Indicators” .Progress in Geography[J]. 2002.11. (6): 1-2 (in Chinese)

[2]http://wenku.baidu.com/view/3dbc540ef12d2af90242e646.html

[3]http://www.stats-sd.gov.cn/tjnj/nj2015/indexch.htm

[4]Yanguang Zhang, Zhenshan Lin, Lingling Chen. "Prediction on the Dynamics of Water Resource Carrying Capacity in Shandong Province” Journal of Natural Resources[J]. 2007.7 (4): 6-7 (in Chinese)

[5]Jianjun Song, Qingjie Zhang, Qiu Ying. “Analysis and prediction of water resource protection with the proposal of counter measures in china in 2020”. Macroeconomics 2004(6):3-6 (in Chinese) 